\title{
CONSTRUCAO DO DISCURSO AUDIOVISUAL NA REPORTAGEM TELEVISIVA
}

(1) Livia Sprizao de Oliveira

Mestrando Universidade Estadual de Londrina, PR

liviaoliveiratv@gmail.com

\section{RESUMO}

A construção textual da reportagem de televisão é um trabalho coletivo em que oralidade e imagem fundem-se na linguagem audiovisual. Pelo próprio imbricamento entre texto verbal e texto visual, significante e significado (BARTHES, 2005) atrelamse causando efeitos de sentido com um nível relevante de argumentatividade. Embora o gênero jornalístico privilegie a função referencial ou denotativa (CHALHUB, 2006), buscando objetividade, as características da linguagem audiovisual propiciam ambiente fértil para funções de caráter subjetivo, apelativo ou emotivo. A entoação do repórter e as escolhas do editor ao selecionar a narrativa imagética que dará significação ao texto oral são ações adjetivadoras, assim como a seleção lexical exerce importante papel na atribuição de sentido ao que se mostra. Pretende-se neste trabalho analisar a construção textual de uma reportagem televisiva a partir dos documentos de processo (SALLES, 2008). Baseando-se no rascunho e no texto final coletados, serão discutidos os elementos que dão suporte aos argumentos do discurso (FIORIN,2000).

\section{INTRODUÇÃO}

Busca-se no texto jornalístico recursos gramaticais que criem efeitos de objetividade e transparência. No caso das reportagens de televisão, os enunciados pretendem provocar a crença de que o que se mostra por meio de imagens é a realidade. Segundo Fiorin (2000), a sintaxe discursiva é o campo da manipulação consciente. "Neste, o falante lança mão de estratégias argumentativas e de outros procedimentos da sintaxe discursiva para criar efeitos de sentido de verdade ou de realidade com vistas a convencer seu interlocutor" (FIORIN, 2000, p. 18)

$\mathrm{Na}$ linguagem audiovisual, utilizada para transmitir notícias televisivas, manipula-se o texto escrito para que se pareça com a língua falada e para que pareça objetivo, apesar das representações imagéticas e da entoação do repórter. Manipulam-se as imagens por meio da escolha da representação do que seria o conteúdo novo e surpreendente, do que se considera notícia.

A construção textual da reportagem de televisão é um trabalho coletivo em que oralidade e imagem fundem-se na linguagem audiovisual. Pelo próprio imbricamento entre texto verbal e texto visual, significante e significado (BARTHES, 2005) atrelamse causando efeitos de sentido com um nível relevante de argumentatividade.

Por meio da análise de uma reportagem cujo texto baseou-se na composição imagética, pretende-se identificar recursos sintáticos e semânticos que oportunizaram a construção do discurso. Se todo discurso contém visões de mundo e valores socialmente construídos, tais elementos são comunicados por meio de recursos de linguagem. Conforme Fiorin (2000), o discurso é a materialização das formações ideológicas, 


\section{SEMINÁRIO DE PESQUISA EM CIÊNCIAS HUMANAS - SEPECH \\ Humanidades, Estado e desafios didático-científicos \\ Londrina, 27 a 29 de julho de 2016}

enquanto o texto é "unicamente um lugar de manipulação consciente em que o homem organiza, da melhor maneira possível, os elementos de expressão que estão a sua disposição para veicular seu discurso. " (FIORIN, 2000, p.41)

Não será possível, neste suporte impresso, explorar elementos altamente argumentativos na linguagem audiovisual, como a variação da voz e as escolhas imagéticas. Mas o texto escrito para ser oralizado fornece material suficiente para que sejam discutidos alguns dos elementos que dão sustentação aos argumentos do discurso.

\section{O TEXTO IMAGÉTICO TELEVISIVO E A REPRESENTAÇÃO DO REAL}

De acordo com Maingueneau, "toda enunciação, mesmo produzida sem a presença de um destinatário, é de fato, marcada por uma interatividade constitutiva, é uma troca, explícita ou implícita, com outros enunciadores, virtuais ou reais" (MAINGUENEAU, 2013, p. 60). Na produção televisiva, o destinatário é virtual e busca-se manter com ele um diálogo simulado por meio de uma narrativa ilustrada por imagens que representam o real. Por se tratar de um meio audiovisual, tal narrativa empresta características da língua falada.

Os produtos televisivos são feitos de imagens tecnicamente produzidas. No gênero telejornal, histórias são relatadas a partir de um texto imagético contextualizado por palavras. Do repórter cinematográfico espera-se capacidade para narrar um evento por meio da gravação de cenas que, encadeadas, representem uma determinada realidade, "um retrato ou uma representação reconhecível de mundo" (NICHOLS, 2005, p. 28).

Diz-se representação da realidade por compreender-se que a realidade é construída com base em valores compartilhados socialmente. Conforme Motta (2005, p.8), “o homem sempre viveu em um 'mundo de segunda mão'. A sua imagem do mundo e de si próprio, em sua maior parte, lhe foi repassada através de algum tipo de conhecimento indireto pelo senso comum, a religião, as artes, a educação formal, a filosofia".

A sequência de imagens registradas pelo repórter cinematográfico é realinhada pelo editor, conforme a intencionalidade comunicacional. Imagens são argumentativas à medida que representam concepções de mundo, tais concepções são construídas pelo repórter cinematográfico por meio dos recursos técnicos utilizados e reinterpretados pelas decisões do editor, que seleciona as representações estéticas do que se quer dizer.

Conclui-se que, assim como os documentários conceituados por Nichols (2005), as reportagens de televisão "podem representar o mundo da mesma forma que um advogado representa os interesses de um cliente: colocam diante de nós a defesa de um determinado ponto de vista ou uma determinada interpretação das provas" (NICHOLS, 2005, p. 30). Sendo assim, as narrativas televisivas veiculam impressões, interpretações de fatos, e apropriam-se de declarações compartilhadas pelos entrevistados, testemunhas destes fatos, para conferir credibilidade aos argumentos.

Emerin e Brasil (2013) reforçam que o principal critério para um fato se tornar notícia, na televisão, é o potencial para gerar imagens. "No telejornalismo, as imagens são fundamentais, aliás, exibir imagens dos acontecimentos o mais próximo de sua ocorrência é a característica principal do jornalismo de TV" (EMERIM E BRASIL, 2013 , p. 27). Mas as imagens não se sustentam sozinhas no fazer telejornalístico. O 


\section{SEMINÁRIO DE PESQUISA EM CIÊNCIAS HUMANAS - SEPECH \\ Humanidades, Estado e desafios didático-científicos \\ Londrina, 27 a 29 de julho de 2016}

texto oral, que simula um diálogo com o telespectador, exerce importante papel contextualizador do enunciado imagético conferindo-lhe sentido.

$\mathrm{Na}$ linguagem audiovisual, a representação do signo pode se dar de modo que um significante verbal invoque um significado imagético e vice-versa, e os planos de expressão e conteúdo alternam-se conforme a necessidade do ato comunicativo (BARTHES, 1992, p. 43). Portanto, se o significado é uma representação psíquica da "coisa", pode-se dizer que no texto televisivo o significado é uma representação imagética da "coisa".

Tal construção textual torna o processo de absorção da informação mais rápido, deixando pouco tempo para reflexão. Conforme Klein (2006, p. 92) isto significa que "as informações não integradas no nível da consciência, exploram-nos emocionalmente e repercutem mais no nível das sensações corporais." Ao compilar representações auditivas e visuais do mundo, a linguagem audiovisual traveste-se de objetividade para veicular conceitos subjetivos.

O texto jornalístico vale-se da função referencial da linguagem (CHALHUB, 2006), com informações claras e definidas, buscando uma descrição objetiva do mundo. Mas ao associar texto imagético e texto oral, criam-se outros efeitos de sentido. A entoação do repórter e a combinação de palavras e imagens podem gerar ambiguidades, conotações e concorrência com outras funções, tais como poética, conativa e emotiva. Pode-se afirmar assim que a linguagem audiovisual é, por essência, adjetivadora.

\section{CONSTRUÇÃO DE ENUNCIADOS COM MÚLTIPLOS ENUNCIADORES}

Segundo Fiorin (2000), "o texto é individual, enquanto o discurso é social”, e "na medida em que é determinado pelas formações ideológicas, o discurso cita outros discursos" (FIORIN, 2000, p. 41). Sendo assim, os discursos são construídos socialmente de acordo com os temas existentes e disponíveis na sociedade em que está inserido.

Na reportagem de televisão, há vários enunciadores, a começar pelos integrantes da equipe envolvida em todo o processo de produção. A construção textual inicia-se na pauta, com as informações prévias fornecidas pelo pauteiro para auxiliar o repórter na busca por informações adicionais. Portanto, partes do enunciado podem estar contidas na pauta. Repórter e repórter cinematográfico criam seus próprios enunciados, que serão amarrados pelo editor, responsável pela finalização do processo.

Mas, além desta equipe, também existem as declarações de terceiros, contidas nas entrevistas, e que também compõem o enunciado. Portanto, além da equipe narradora, há também enunciadores secundários manifestando suas próprias visões do mundo e dos fatos (MAINGUENEAU, 2013). Logo, há várias ideologias contidas em um mesmo texto televisivo, todas elas inseridas em um mesmo contexto social.

\section{REFERÊNCIAS IMAGÉTICAS NA ELABORAÇ̃̃O DO DISCURSO}

O texto a ser analisado foi construído em equipe. A proposta inicial da produção era que um repórter e um repórter cinematográfico acompanhassem um grupo de voluntários do Jipe Clube de Londrina que prestava auxílio às vítimas da enchente que 


\section{SEMINÁRIO DE PESQUISA EM CIÊNCIAS HUMANAS - SEPECH \\ Humanidades, Estado e desafios didático-científicos \\ Londrina, 27 a 29 de julho de 2016}

destruiu pontes e estradas rurais da cidade no dia 11 de janeiro de 2016. Mas havia espaço para apenas um profissional da imprensa.

Decidiu-se que o repórter cinematográfico Flávio Garcia seguiria com os "jipeiros", para registrar a ação. O objetivo era fazer imagens dos pontos aonde os carros comuns da reportagem não conseguiriam chegar, por conta das más condições da estrada. E, para dar uma dimensão humana à tragédia, pretendia-se contar a história de uma família que tentava voltar para casa após o temporal.

$\mathrm{O}$ repórter cinematográfico registrou, em áudio e vídeo, os momentos que antecederam a partida da caravana e o percurso. Em alguns momentos, Garcia interveio, fazendo perguntas aos motoristas, às famílias que recebiam ajuda, e às pessoas que o grupo encontrou durante a viagem. Estas entrevistas, chamadas de sonoras, ajudaram na contextualização das imagens.

Foram aproximadamente seis horas de viagem e 50 minutos de imagens gravadas no cartão de memória, que resultaram em uma reportagem de pouco mais de oito minutos. É inviável transpor para o presente estudo o conteúdo coletado pelo repórter cinematográfico, assim como a reportagem editada, devido à incompatibilidade entre as mídias. No entanto, foi possível recuperar parte dos documentos de processo da produção da reportagem porque o primeiro rascunho foi compartilhado em uma rede social utilizada pela equipe.

O repórter cinematográfico fez um relato oral, por telefone, que foi transcrito por uma editora. Ela repassou o relatório por meio de um aplicativo eletrônico onde são compartilhadas informações pelo grupo de colegas de trabalho. Este documento de processo (SALLES, 2008) é importante porque serviu de instrumento contextualizador para o trabalho de edição e é um recurso de memória.

Segundo Maingueneau (2013), três tipos de contexto podem fornecer elementos necessários para a interpretação: a) o ambiente físico ou contexto situacional; b) o cotexto, que mobiliza a memória do intérprete sobre a totalidade do enunciado; e c) o conhecimento de mundo, que é o conjunto de saberes anteriores à enunciação. Por meio do relatório, o editor conseguiu identificar o trajeto da equipe e os locais onde foram gravadas as imagens, teve conhecimento sobre as cenas que mais impressionaram o repórter cinematográfico. As informações vêm a compor o conhecimento compartilhado de mundo.

Segue transcrição o relatório repassado à equipe por meio do aplicativo:

RELATÓRIO DO FLÁVIO... uma caravana com voluntários do Jipe Clube de Londrina, que disponibilizou os veículos saiu de Londrina por volta das 5 da tarde para levar uma família até o Assentamento Eli Vive, perto de Lerroville. TEM SONORA COM A FAMÍLIA... Na saída de Londrina, pegaram a Estrada do Galo, que liga ao Patrimônio Selva... estrada de chão... o trecho estava interditado porque a cabeceira da ponte foi levada pelas águas... VOLTARAM... Foram pela estrada que liga a Maravilha... de lá até Paiquerê... Lá Flávio ENTREVISTOU PESSOAS NO PONTO DE ÔNIBUS para saber a situação... Na Maravilha, cenas de destruição... RIBEIRÃO DOS APERTADOS ainda cheio... por onde passou deixou rastros... Chegaram à PR 445, no trecho interditado - Ribeirão Cafezal... (depois parece que foi liberado... tem que confirmar)... Entraram na estrada da Pedreira Guaravera... até o assentamento. No barraco, tudo 


\section{SEMINÁRIO DE PESQUISA EM CIÊNCIAS HUMANAS - SEPECH \\ Humanidades, Estado e desafios didático-científicos \\ Londrina, 27 a 29 de julho de 2016}

inundado e um cachorro morto. Cena horrível... Defesa Civil deixou lona para a família... Partiram para São Luiz e Patrimônio Regina, entraram pela Estrada Iraúna... ENCONTROU CAMINHÃO ATOLADO... Trator tentando puxar... ERA CAMINHÃO COM RAÇÃO para levar à uma Granja de São Luiz... Iriam chamar um segundo trator... FLÁVIO ACHA que vai o caminhão vai passar a noite lá... FLÁVIO PERCORREU $80 \mathrm{KM}$, entre asfalto e estrada de chão... e ficou impressionado com a força da água, descreveu como se fosse uma bomba jogada nos pontos destruídos...

Ao conferir o relatório, o repórter cinematográfico fez duas correções:

Estrada Itaúna até s. Luís

Família foi levada depois do assentamento

O relatório foi feito à noite para edição na manhã seguinte. $\mathrm{O}$ editor que assumiu o turno usou as informações compartilhadas no grupo do aplicativo para orientar-se em relação à cronologia dos fatos e aos locais visitados pelo repórter cinematográfico. Mas para construir o texto, Diogo Hutt precisou assistir às imagens e ouvir as entrevistas. Segue transcrição da reportagem que foi ao ar:

A AVENTURA COMEÇA NA SEDE DA GUARDA MUNICIPAL, NO LAGO IGAPÓ. // LÁ NOSSA EQUIPE ENCONTROU A FAMÍLIA DO VALDECIR, UM AGRICULTOR QUE $H A ́$ DOIS DIAS ESPERAVA AJUDA PRA VOLTAR PRA CASA.//

Entrevista com Valdecir Mendonça, agricultor

Entrevista com Loiri Sottle, agricultor

A FAMÍLIA ESTAVA VISITANDO PARENTES EM FRANCISCO BELTRÃO.// QUANDO VOLTOU PRA CASA, UMA SUPRESA: AS ESTRADAS ESTAVAM INTERDITADAS.// ONTEM A AJUDA CHEGOU COM ESSA GALERA DO JIPE CLUBE DE LONDRINA.

Entrevista com Romeu Almeida Ribas Neto - voluntário jipe clube ALÉM DO VALDECIR, OUTRAS FAMÍLIAS APROVEITARAM A CARONA.// FORAM OITO JIPES.// UM SÓ PARA LEVAR OS GUARDAS MUNICIPAIS, QUE FAZEM PARTE DA DEFESA CIVIL E ACOMPANHARAM TUDO.// MALAS DEVIDAMENTE GUARDADAS, FAMÍLIA ACOMODADA, É HORA DE PARTIR.// O TRECHO DE ASFALTO FOI CURTO.// NA SAIIDA DE LONDRINA AS EQUIPES ENTRARAM NA ESTRADA DO GALO, QUE DÁ ACESSO AO PATRIMÔNIO SELVA. COMEÇA O BARRO E MUITO BURACO. // ALGUNS MINUTOS DEPOIS A COMITIVA TEM QUE PARAR.// BAMBUS SOBRE A PONTE IMPEDEM A PASSAGEM.// A EXPLICAÇÃO ESTÁ NO OUTRO LADO.// A ÁGUA LEVOU UMA DAS CABECEIRAS.// FIM DA LINHA.// MAS OS JIPEIROS NÃO DESISTEM.//

Entrevista com guarda municipal

O CAMINHO FICOU MAIS LONGO. PARA IR A PAIQUERE, PRIMEIRO OS JIPEIROS TERÃO QUE PASSAR POR 


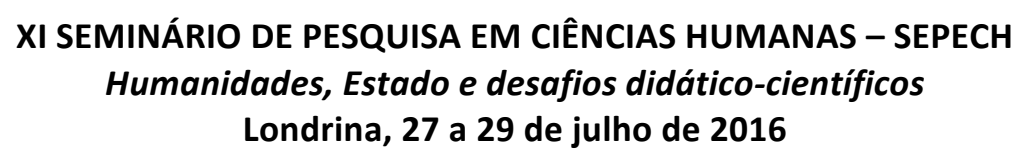

MARAVILHA.// NO CAMINHO O FISCAL DO D.E.R. DÁ A BOA NOTÍCIA:

Entrevista com fiscal do DER

NA ESTRADA, APESAR DOS ESTRAGOS, A NATUREZA ENCANTA//

Entra comentário do Vergílio A CONVERSA TEM QUE SER INTERROMPIDA. // É PRECISO PRESTAR ATENÇÃO NA ESTRADA.// O PERIGO ESTÁ LOGO À FRENTE.// UMA CRATERA GIGANTESCA SE FORMOU PRÓXIMO AO RIO.// VERGÍLIO PASSA COM CUIDADO... E A VIAGEM CONTINUA...//

NO DISTRITO DE PAIQUERÊ, ASSIM QUE OS MORADORES PERCEBEM A PRESENÇA DO NOSSO CINEGRAFISTA, NÃO PERDEM A OPORTUNIDADE://

Áudio reivindicações moradores

DE VOLTA AO ASFALTO, OS CONES INDICAM PERIGO À FRENTE.// É A PONTE SOBRE O RIO TAQUARA.// PARTE DA PROTEÇÃO LATERAL CAIU.// O RIO PERMANECE BEM ACIMA DO NÍVEL NORMAL, OS TRONCOS E GALHOS CAÍDOS INDICAM ONDE A ÁGUA CHEGOU.//EM VÁRIOS TRECHOS DA PR 445 PONTES FORAM LIBERADAS DEPOIS DE OBRAS PALIATIVAS.// EM VÁRIOS PONTOS O TRÂNSITO SEGUE EM MEIA PISTA, COMO AQUI, ONDE O BARRANCO DESMORONOU E A TERRA INVADIU O ASFALTO.// OS JIPEIROS CHEGAM AO ASSENTAMENTO ELI VIVE.// MOSTRAM TODA A HABILIDADE EM DIVERSOS ATOLEIROS, PRATICAMENTE ESCALAM GIGANTESCOS BURACOS NA ESTRADA.// PARA CHEGAR NA CASA DO SEU VALDECIR, O JEITO É ENTRAR NO MATO.// MISSÃO CUMPRIDA.// A FAMÍLIA ESTÁ DE VOLTA, EM CASA.//

Entrevista Loiri Sottle, agricultor

OS GUARDAS MUNICIPAIS ENTREGAM LONA PARA COBRIR A HUMILDE CASA//

ANTES DE VOLTAR PARA LONDRINA, OS AGENTES DA DEFESA CIVIL DECIDEM MUDAR OS PLANOS.// FAMÍLIAS ESTARIAM ISOLADAS EM DISTRITOS PRÓXIMOS.//

Entrevista guarda municipal

COMEÇA A ANOITECER E AS DIFICULDADES AUMENTAM. // AS LUZES NA FRENTE SÃO DE UM TRATOR PARADO NO MEIO DA ESTRADA QUE LIGA IRERE A TAQUARUNA. // AS EQUIPES PARAM.// OS GUARDAS DESEMBARCAM PARA VER O QUE ESTÁ ACONTECENDO.// ERA UM CAMINHÃO ATOLADO.// NEM O TRATOR CONSEGUIA TIRAR.// O CAMINHONEIRO TERÁ QUE PASSAR A NOITE AQUI.// ELE TENTAVA LEVAR RAÇÃO PARA A PROPRIEDADES RURAIS.

Entrevista produtor rural

CANSADOS E SEM ESTRUTURA PARA IMPROVISAR UM ACAMPAMENTO, AS EQUIPES DECIDEM VOLTAR.// AGORA A DEFESA CIVIL SABE A REAL SITUAÇÃO DOS PRINCIPAIS DISTRITOS DE LONDRINA E, GRAÇAS À AJUDA DO JIPE CLUBE, PODE TRAÇAR NOVAS ESTRATÉGIAS. 


\section{SEMINÁRIO DE PESQUISA EM CIÊNCIAS HUMANAS - SEPECH \\ Humanidades, Estado e desafios didático-científicos \\ Londrina, 27 a 29 de julho de 2016}

A seleção lexical de alguns substantivos, destacados em negrito, dá o ritmo da narrativa desde o início do texto. Palavras como "aventura", "galera", "surpresa" e "jipeiros" dão ao enunciado certa informalidade, que condiz com a situação mostrada na reportagem. É também uma forma criar um ambiente de emoção e suspense. Mas este não é o único campo lexical dominante no texto.

Há também, na seleção de substantivos, palavras como "perigo", "barro", "lama", "natureza", "buracos", "cratera" que posicionam o telespectador diante das dificuldades encontradas pela equipe, causadas por fenômenos naturais, mas que precisavam ser dominadas e ultrapassadas pelos voluntários da referida comitiva.

A seleção lexical é a escolha de palavras de um determinado campo semântico de modo que tragam um sentido implícito ao texto. Segundo Koch (1987, p. 156), "a escolha de um determinado termo pode servir de índice de distinção, de familiaridade, de simplicidade, ou pode estar a serviço da argumentação, situando melhor o objeto do discurso dentro de determinada categoria, do que o faria o uso de um sinônimo". Além dos substantivos, fazem parte da seleção lexical também os verbos e os adjetivos. Estes últimos serão analisados na sequência, sob outra perspectiva.

Em negrito sublinhado estão apontados os adjetivos. Nota-se que, em algumas situações, eles aparecem antepostos ao substantivo, realçando o teor de subjetividade da construção. É o caso de "gigantescos buracos", "boa notícia", "real situação" e "humilde casa". Nesta posição, os adjetivos têm claramente o objetivo de provocar emoção.

Já nas situações em que os adjetivos são postos depois do substantivo, as qualidades são menos argumentativas e mais objetivas, tendendo à descrição. Observase isto em "trator parado", "caminhão atolado", "guardas municipais" e "obras paliativas". Nestes casos, os adjetivos têm uma função mais informativa, descritiva.

Neves (2000), na Gramática de usos do português, distingue os adjetivos em qualificadores e classificadores. Os primeiros têm caráter vago e subjetivo, enquanto os segundos têm caráter não vago, objetivo. No texto em questão, os adjetivos qualificadores estão antepostos ao substantivo, enquanto os pospostos classificam o substantivo de maneira relacional.

O uso da preposição contraída "pra", em vez de "para", é uma forma de facilitar a oralização do texto escrito e aproximá-lo da língua falada. As locuções adverbiais de lugar, sublinhados no texto, também são recursos essenciais na reportagem de televisão como dêiticos espaciais que situam o telespectador no espaço dos acontecimentos.

Chama a atenção a grande quantidade de verbos, indicados em itálico, priorizando as ações. Essa é uma característica do texto jornalístico de televisão. Percebe-se, no entanto, que os tempos verbais variam ao longo da narrativa. Quando o enunciador pretende se distanciar do fato, descrevendo a cena de maneira mais objetiva, é utilizado o tempo pretérito; mas quando a intenção é causar tensão, usa o tempo presente.

Ao usar o presente, o narrador traz o telespectador para o momento da ação, um recurso altamente argumentativo. Nos momentos em que o verbo é usado no presente, o repórter cinematográfico está com a câmera em ângulo subjetivo, ou seja, ele está dentro da ação, faz parte dela, grava imagens do ponto de vista de um dos integrantes da comitiva, como passageiro do jipe, e não como um observador externo, que grava de um ponto objetivo, fora da cena. Ao ver imagens gravadas de um ângulo subjetivo e ouvir a 


\section{SEMINÁRIO DE PESQUISA EM CIÊNCIAS HUMANAS - SEPECH \\ Humanidades, Estado e desafios didático-científicos \\ Londrina, 27 a 29 de julho de 2016}

narração no tempo presente, o olhar do telespectador também é conduzido para dentro da ação.

$\mathrm{Na}$ reportagem em análise, as entrevistas são introduzidas na forma de discurso direto, com a intenção de criar efeito de objetividade, apresentando exatamente as palavras do enunciador (MAINGUENEAU, 2013). Os créditos para o enunciador vêm em forma de legenda, na maioria das vezes. A única exceção é a entrevista do fiscal do D.E.R., que é antecedido por uma curta introdução.

\section{CONSIDERAÇÕES FINAIS}

O texto jornalístico utiliza-se de recursos gramaticais que forjam uma objetividade textual. A principal função de linguagem utilizada é a referencial. No entanto, quando se trata da linguagem jornalística na reportagem de televisão, soma-se ao texto escrito para ser falado as imagens e a entoação do repórter. A combinação desses fatores torna a linguagem audiovisual complexa e argumentativa apesar dos esforços para eximi-la de opinião.

$\mathrm{O}$ texto analisado neste artigo foi escrito com base em um texto imagético previamente construído por um repórter cinematográfico e posteriormente editado a partir da combinação entre palavra e representação visual. Demonstrou-se, por meio dos documentos de processo, que a construção da reportagem é feita em equipe. Mas além dos enunciadores internos, participantes ativos da produção, há também enunciadores secundários, que são os entrevistados ouvidos durante a elaboração do produto televisivo.

O editor, que define o que vai ao ar, é o principal autor do texto em questão. Por meio das decisões desse profissional, percebe-se a voz, a personalidade, desse enunciador. A despeito da proposta de representação do real, inerente à prática jornalística, o uso dos elementos gramaticais e das imagens disponíveis revelam a intencionalidade comunicacional.

A seleção lexical, os diferentes empregos dos adjetivos e a manipulação dos tempos verbais, indicam a mobilização de recursos que visam persuadir e manter a atenção dos telespectadores voltada para o que se quer dizer e mostrar. Sendo assim, as funções emotiva e conativa fazem fundo à função referencial, demonstrando que as reportagens de televisão são veiculadoras de discurso mesmo em situações em que a narrativa tende à descrição dos recortes da realidade, interpretando fatos com base em conceitos socialmente compartilhados.

\section{REFERÊNCIAS}

BARTHES, Roland. Elementos de semiologia. Trad. Izidoro Blikstein. São Paulo: Cultrix, 1992

CHALHUB, Samira. Funções da linguagem. 12.a ed. São Paulo: Ática, 2006 


\section{SEMINÁRIO DE PESQUISA EM CIÊNCIAS HUMANAS - SEPECH \\ Humanidades, Estado e desafios didático-científicos \\ Londrina, 27 a 29 de julho de 2016}

EMERIN, Cárlida; BRASIL, Antônio. Considerações sobre o conceito de coberturas em telejornalismo. In: EMERIN, Cárlida; PAULINO, Rita. Ensaios sobre televisão e telejornalismo. Florianópolis: Insular, 2013. P. 21-38

FIORIN, José Luiz. Linguagem e ideologia. 7.a ed. São Paulo: Ática, 2000

KLEIN, Alberto. Projeções midiáticas do olhar. Comunicação midiática, n.o 6, p. 8796, 2006

KOCH, Ingedore G. Villaça. Argumentação e Linguagem. 2.a ed. São Paulo: Cortez, 1987

MAINGENEAU, Dominique. Análise de textos de comunicação. 6.a ed. São Paulo: Editora Cortez, 2013

MOTTA, Luiz Gonzaga. O trabalho simbólico da notícia. Líbero - Ano VIII, n.o 15/16, p. $8-15,2005$

NEVES, Maria Helena de Moura. Gramática de usos do português. São Paulo: Unesp, 2000

NICHOLS, Bill. Introdução ao documentário. Trad. Mônica Saddy Martins. Campinas, SP: Papirus, 2005 